\title{
Pemeliharaan Fisik Taman Nostalgia Kota Kupang Provinsi Nusa Tenggara Timur
}

\author{
VENANSIUS CH. FIRST RUBA ${ }^{1 *}$, NI WAYAN FEBRIANA UTAMI ${ }^{1}$, \\ GEDE MENAKA ADNYANA ${ }^{1}$
}

1. Program Studi Agroekoteknologi, Fakultas Pertanian, Universitas Udayana, JI. P.B Sudirman, Denpasar, 80362 Bali, Indonesia

${ }^{*} E-$-mail : venanruba@ymail.com

\section{ABSTRACT \\ Physical Maintenance in Nostalgia Park, Kupang City, East Nusa Tenggara Province}

Nostalgia Park is located in Frans Seda Street, Kupang City. It is a city park built by the local government as the place for the National Peace Monument in Kupang. This park is managed by the local government and it has been the city park in Kupang, Nusa Tenggara Timur Province. The purpose of this research are to know the physical maintenance system of soft materials and hard materials, the users' perspective of the physical maintenance system, and the obstacles in doing the physic maintenance in Nostalgia Park. This methods of research are done by doing observation, using questionaire to determine the visitors' perceptions, identifying the physical maintenance system with the local government, and getting some literatures to complete the data of this research. Results of research indicated that the local government has done a good physical maintenance for soft materials and hard materials in Nostalgia Park. This can be seen by the result of the visitors' perceptions and interview with the local government.

Key words: East Nusa Tenggara, Kupang City, Nostalgia Park, physical maintenance system.

\section{Pendahuluan}

\subsection{Latar Belakang}

Menurut UU No. 26 Tahun 2007 tentang Penataan Ruang, kawasan perkotaan merupakan wilayah yang mempunyai kegiatan utama bukan pertanian dengan susunan fungsi kawasan sebagai tempat permukiman perkotaan, pemusatan dan distribusi pelayanan jasa pemerintahan, pelayanan sosial, dan kegiatan ekonomi. Pencemaran air, pencemaran udara, dan pencemaran tanah adalah dampak dari tingginya aktivitas penduduk yang tinggi. Untuk meminimalkan dampak terhadap lingkungan, maka dibangun ruang terbuka hijau. 
Berdasarkan Pasal 1 angka 31 UU No 26 Tahun 2007 Tentang Penataan Ruang mendefinisikan Ruang Terbuka Hijau (RTH) sebagai area memanjang/jalur dan atau mengelompok yang penggunaannya lebih bersifat terbuka, tempat tumbuh tanaman, baik yang tumbuh secara alamiah, maupun yang sengaja ditanam. Dalam Pasal 28 sampai dengan pasal 30 UU No. 26 Tahun 2007 menyatakan bahwa proporsi ruang terbuka hijau pada wilayah kota minimal $30 \%$ dan proporsi ruang terbuka hijau publik pada wilayah kota minimal $20 \%$ dari luas wilayah kota. Taman Nostalgia merupakan salah satu ruang terbuka hijau berupa taman kota yang terdapat di Kota Kupang. Taman Nostalgia terletak di Kelurahan Kelapa Lima, Kecamatan Kelapa Lima tepatnya di Pusat Kota Kupang. Taman Nostalgia memiliki Gong Perdamaian Nusantara (GPN) yang menjadi simbol perdamaian di Indonesia. Taman Nostalgia dilengkapi dengan beberapa fasilitas penunjang, antara lain lapangan basket, jogging track, gazebo dan bangku - bangku taman. Perawatan dan pemeliharaan fasilitas dan tanaman di Taman Nostalgia masih kurang optimal, sehingga menyebabkan banyak tanaman dan fasilitas yang tidak terawat.

Peranan Taman Nostalgia adalah sebagai taman rekreasi dan olahraga bagi masyarakat Kota Kupang. Peranan sebagai taman rekreasi dan olahraga bagi masyarakat Kota Kupang, mengharuskan adanya pengelolaan taman yang lebih optimal, terutama pemeliharaan fisik taman. Perhatian terhadap penataan dan pemeliharaan fisik taman menjadi hal yang diutamakan untuk menjaga keberlangsungan dan eksistensi Taman Nostalgia sebagai taman kota dan ruang terbuka hijau kota di Kota Kupang, Provinsi Nusa Tenggara Timur.

\subsection{Rumusan Masalah}

1. Bagaimana sistem pemeliharaan fisik hard materials dan soft materials oleh pihak pengelola di Taman Nostalgia?

2. Bagaimana persepsi pengunjung terhadap kondisi fisik di Taman Nostalgia?

3. Apa saja permasalahan dan faktor - faktor penghambat dalam kegiatan pemeliharaan fisik di Taman Nostalgia?

\subsection{Tujuan Penulisan}

1. Mengetahui sistem pemeliharaan fisik hard materials dan soft materials oleh pihak pengelola di Taman Nostalgia

2. Mengetahui persepsi pengunjung terhadap pemeliharaan fisik di Taman Nostalgia.

3.Mengetahui permasalahan dan faktor - faktor penghambat dalam kegiatan pemeliharaan fisik di Taman Nostalgia.

\section{Bahan dan Metode}

\subsection{Tempat dan Waktu Penelitian}

Penelitian terhadap pemeliharaan fisik taman dilakukan di Taman Nostalgia, Kecamatan Kelapa Lima, Kota Kupang, Provinsi Nusa Tenggara Timur. Penelitian ini dilaksanakan selama 2 bulan dimulai pada bulan Februari 2014 sampai Maret 2015. 


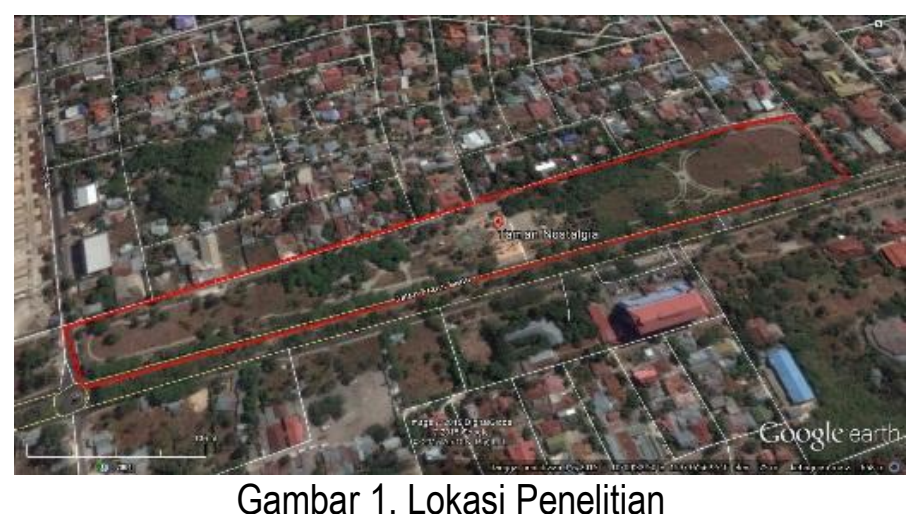

\subsection{Bahan dan Alat}

Alat dan bahan yang digunakan dalam penelitian ini adalah lembar kuesioner, kamera digital, alat tulis dan komputer dengan software Microsoft excel untuk melakukan pengolahan data.

\subsection{Metode Pengumpulan Data}

a. Studi kepustakaan, yakni dokumen dan sumber pustaka sistem pemeliharaan fisik taman.

b. Observasi, yakni pengamatan langsung di Taman Nostalgia Kota Kupang.

c. Wawancara, yakni wawancara dengan pihak pengelola Taman Nostalgia.

d. Penyebaran kuesioner kepada pengunjung Taman Nostalgia.

\subsection{Metode Analisis}

Kuesioner mengenai pemeliharaan fisik di Taman Nostalgia menggunakan Skala likert. Responden menentukan tingkat persetujuan terhadap suatu pertanyaan dengan memilih salah satu dari lima (5) pilihan yang tersedia (sangat baik, cukup baik, baik, kurang baik, tidak baik) dengan kategori penilaian sebagai berikut.

Skor 1 ( 0\% - 19,99\%) : Tidak Baik

Skor $2(20 \%-39,99 \%)$ : Kurang Baik

Skor $3(40 \%-59,99 \%)$ : Baik

Skor $4(60 \%-79,99 \%)$ : Cukup Baik

Skor $5(80 \%-100 \%)$ : Sangat Baik

Hasil penyebaran kuesioner akan diakumulasikan dala bentuk persentase dengan menggunakan rumus index:

$$
\text { rumus index }=\frac{\text { total skor penilaian }}{\text { skor terting gi }} \times 100 \%
$$

Hasil yang diperoleh melalui penggunaan rumus di atas, akan ditampilkan dalam bentuk tabel dan diagram lingkaran atau grafik dan data hasil wawancara dengan pengelola taman dan data dari dokumen - dokumen mengenai sistem pemeliharaan fisik dan kendala yang ada dalam pemeliharaan fisik taman, akan diolah secara deskriptif untuk menjadikan informasi sebagai suatu kesatuan yang utuh. 


\section{Hasil dan Pembahasan}

\subsection{Gambaran Umum Taman Nostalgia}

Taman Nostalgia merupakan taman yang dirancang untuk mendukung keberadaan Monumen Gong Perdamaian Nusantara di Kota Kupang. Taman Nostalgia diresmikan pada tanggal 9 Februari 2011. Monumen Gong Perdamaian Nusantara yang terdapat di Taman Nostalgia merupakan salah satu dari 33 unit yang disebar di 33 provinsi di Indonesia.

Taman Nostalgia pada awalnya merupakan ruang terbuka hijau , berupa hutan kota. Ruang terbuka hijau ini kemudian dialihfungsikan menjadi taman sebagai lokasi penempatan Monumen Gong Perdamaian Nusantara. Taman ini pada awalnya dibangun sehubungan dengan kedatangan Presiden SBY pada tahun 2011 untuk meresmikan Monumen Gong Perdamaian Nasional di Kota Kupang. Taman ini kemudian tidak terawat. Hal ini disebabkan oleh tidak adanya pihak yang bertanggung jawab secara utuh terhadap pengelolaan Taman Nostalgia. Taman ini pada awalnya dikelola oleh Pemerintah Provinsi NTT. Akan tetapi, taman ini kemudian diminta untuk dikelola oleh Pemerintah Kota Kupang karena keberadaan taman tersebut di wilayah pemerintahan Pemerintah Kota (Hayon, 2013)

Taman Nostalgia terletak pada ketinggian 100 - 200 mdpl. Topografi Taman Nostalgia relatif datar dengan kemiringan berkisar antara $0-5 \%$. Ketersediaan air di Taman Nostalgia berasal dari PDAM. Pengelola Taman Nostalgia memanfaatkan air yang berasal dari sebagai penyedia air utama. Sumber air PDAM tersebut ditampung dan kemudian disalurkan ke area - area tertentu di taman untuk melakukan aktivitas penyiraman terhadap tanaman yang terdapat pada Taman Nostalgia. Vegetasi yang ada di Taman Nostalgia didominasi oleh pohon karena keadaan iklim Kota Kupang yang cukup panas. Vegetasi pohon berada di bagian tepi taman, sedangkan vegetasi semak, perdu, dan ground cover berada di area tengah taman.

\subsection{Profil Dinas Kebersihan dan Pertamanan Kota Kupang}

Dinas Kebersihan dan Pertamanan Kota Kupang memiliki visi, yakni mewujudkan Kota Kupang sebagai kota yang bersih dan asri dengan meningkatkan peran serta masyarakat dalam pengelolaan kebersihan dan pertamanan (Dinas Kebersihan dan Pertamanan, 2015). Untuk mencapai visi tersebut, maka misi yang dilakukan oleh DKP Kota Kupang, yaitu :

1. Meningkatkan kualitas sumber daya manusia dan manajemen pelayanan kebersihan pertamanan Kota Kupang.

2. Meningkatkan kesadaran dan peran serta masyarakat dalam pengelolaan kebersihan dan pertamanan berbasis komunitas.

3. Meningkatkan peran serta dunia usaha dalam pengelolaan kebersihan dan pertamanan.

4. Meningkatkan prasarana dan sarana kebersihan dan pertamanan. 
Dinas Kebersihan dan Pertamanan memiliki 3 bidang utama, yakni bidang pertamanan, bidang pengelolaan sampah, dan bidang sarana dan prasarana yang memiliki sub bidang masing - masing.

\subsection{Pemeliharaan Fisik Taman Nostalgia}

\subsubsection{Pemeliharaan Soft Materials Taman Nostalgia}

a. Pembersihan areal taman

Kegiatan pembersihan area taman dilakukan setiap hari, yaitu dengan menyapu area rumput pada sore hari. Alat yang digunakan adalah sapu lidi, karung plastik, dan gerobak dorong. Pembersihan area taman, terutama rumput sering dilakukan setelah adanya pemangkasan terhadap tanaman semak dan perdu, serta rerumputan yang dilakukan apabila kondisi tanaman sudah tidak baik. Sisa hasil pemangkasan yang berukuran besar dimasukkan ke dalam plastik atau diletakkan di sisi terluar taman agar mempermudah pengangkutan ke truk sampah. Sedangkan sisa tanaman berupa daun - daun yang rontok, diletakkan di bawah pohon agar menjadi pupuk bagi tanaman tersebut. Tenaga kerja yang melakukan pembersihan areal taman biasanya merupakan tenaga kerja perempuan dan dilakukan pada sore hari.

b. Penyiraman

Penyiraman dapat dilakukan pada pagi hari atau sore hari. Penyiraman tanaman di Taman Nostalgia biasanya dilakukan setiap hari pada sore hari menggunakan selang air. Air dialirkan ke tanaman melalui selang air. Akan tetapi, pada musim kemarau, penyiraman tanaman di Taman Nostalgia dilakukan pada pagi hari atau sore hari dengan menggunakan mobil tangki air karena ketersediaan air yang kurang pada musim tersebut. Penyiraman tanaman biasanya dilakukan oleh para petugas yang berada di Taman Nostalgia.

c. Pemupukan

Aktivitas pemupukan tanaman di Taman Nostalgia menggunakan pupuk organik. Pupuk berasal dari sisa - sisa tanaman yang dipangkas. Sisa - sisa hasil pemangkasan tanaman disimpan dan ditimbun di bagian bawah tanaman dengan tujuan agar melapuk dan kemudian dapat dimanfaatkan sebagai pupuk bagi tanaman. Aktivitas pemupukan dilakukan oleh para petugas yang ada di Taman Nostalgia baik tenaga kerja pria maupun tenaga kerja perempuan.

\section{d. Pemangkasan}

Pemangkasan semak maupun tanaman perdu bertujuan untuk mempertahankan bentuk tanaman dan keindahan tanaman tersebut. Tenaga kerja yang biasa melaksanakan kegiatan pemangkasan semak adalah tenaga kerja pria berjumlah 1 orang dengan menggunakan gunting rumput.

Pemangkasan rumput dilakukan untuk menjaga kondisi dan ukuran rumput agar tetap terlihat rapi. Alat yang digunakan untuk melakukan pemangkasan rumput adalah mesin potong rumput gendong. Pemangkasan rumput biasanya dilakukan oleh 1-2 orang tenaga kerja pria pada sore hari dan bersifat insidental. Para pekerja tidak menggunakan pakaian kerja, sehingga hal ini berpengaruh terhadap keselematan kerja di lapangan. 

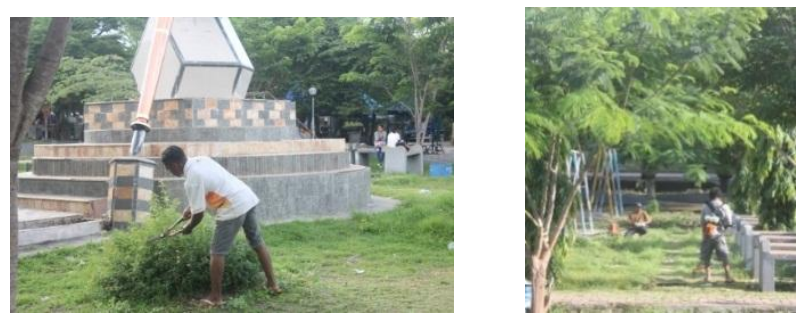

Gambar 2. Aktivitas Pemangkasan Tanaman di Taman Nostalgia

e. Pemberantasan hama dan penyakit

Aktivitas pemberantasan hama dan penyakit pada tanaman di Taman Nostalgia, dilakukan secara insidental. Hama yang paling banyak menyerang tanaman di Taman Nostalgia adalah ulat dan serangga, sedangkan penyakit yang sering menyerang tanaman adalah penyakit bercak daun. Apabila tanaman terlihat mulai terkena gejala penyakit ataupun serangan hama, maka akan segera dilakukan pemberantasan hama dan penyakit. Pemberantasan hama dan penyakit dilakukan dengan cara membuang atau mematahkan bagian tanaman yang terserang untuk menghindari penyebaran lebih luas ke bagian tanaman lainnya. Tenaga kerja pria bertugas untuk melakukan pengecekan dan pemberantasan tanaman yang terserang hama atau penyakit di taman.

\subsubsection{Pemeliharaan Hard Materials Taman Nostalgia}

a. Pemeliharaan Bangunan dan Fasilitas Taman

Pemeliharaan bangunan dan fasilitas taman yang dilakukan di Taman Nostalgia adalah pembersihan toilet, perbaikan fasilitas yang sudah tidak berfungsi, dan pengecatan pada fasilitas yang warnanya telah memudar.

Pembersihan toilet dilakukan oleh petugas sesuai dengan jadwal yang telah ditetapkan oleh Dinas Kebersihan dan Pertamanan Kota Kupang. Petugas yang bertugas mengawasi kondisi area Taman Nostalgia, juga bertugas untuk melakukan pembersihan di area toilet di Taman Nostalgia. Toilet di Taman Nostalgia berjumlah 2 buah dan yang bisa digunakan berjumlah 1 buah, sementara satunya lagi masih dalam tahap penyelesaian pembangunan. Pembersihan toilet dilakukan dengan tujuan untuk menjaga kondisi toilet agar tetap bersih dan menarik untuk digunakan. Banyak fasilitas taman yang juga memiliki kondisi yang kurang baik dan rusak, misalnya lampu taman dan lapangan basket. Selain itu, aksi corat-mencoret juga terjadi pada fasilitas taman, seperti gazebo dan bangku taman. Bentuk aktivitas pemeliharaan fasilitas taman yang biasa dilakukan di taman adalah pengecatan kembali fasilitas taman, seperti bangku taman yang warnanya telah memudar. 

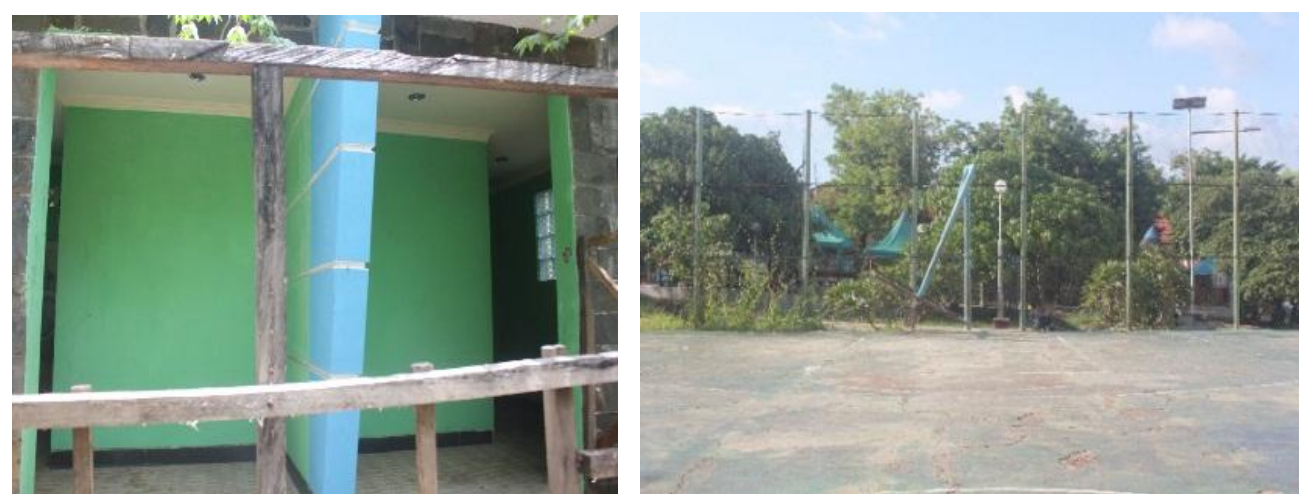

Gambar 3. Toilet yang Masih dalam Tahap Penyelesain dan Lapangan Basket yang Rusak

b. Pemeliharaan Perkerasan Taman

Untuk menjaga area perkerasan tetap bersih, dilakukan penyapuan perkerasan pada sore hari. Penyapuan seluruh area taman dilakukan oleh tenaga kerja perempuan. Jumlah tenaga kerja perempuan untuk kegiatan penyapuan di Taman Nostalgia bervariasi dan tergantung dengan kondisi lapangan. Sasaran dari kegiatan penyapuan adalah sampah plastik, sampah hasil pemangkasan tanaman, dan daun - daun yang rontok.

Kondisi perkerasan sudah banyak mengalami kerusakan, sehingga menyebabkan estetika taman berkurang. Perkerasan yang telah rusak sebaiknya diganti dengan yang baru agar perkerasan dapat digunakan secara aman dan nyaman.

\subsection{Persepsi Pengunjung mengenai Pemeliharaan Fisik}

\subsubsection{Persepsi Pengunjung mengenai Kondisi Fisik Hard Materials}

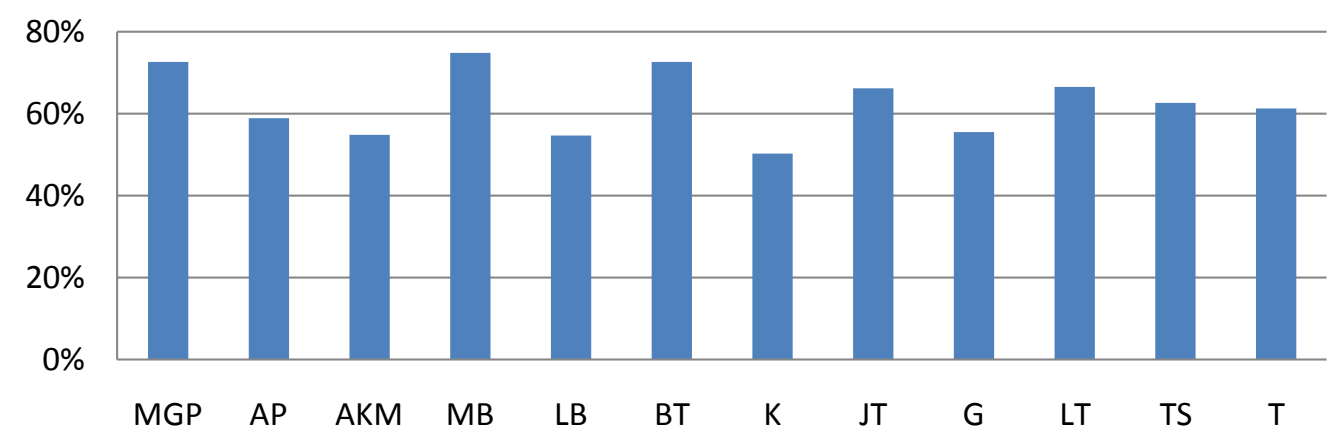

Keterangan : MGP : Monumen Gong Perdamaian, AP : Area Parkir, AKM : Area Kantin Makanan, MB : Monumen Buku, LB : Lapangan Basket, BT : Bangku Taman, K : Kolam, JT : Jogging track, G : Gazebo, LT : Lampu Taman, TS : Tempat Sampah, T : Toilet.

\section{Gambar 4. Penilaian Kondisi Fisik Hard Material}

Berdasarkan grafik di atas, dapat dilihat bahwa kondisi fisik hard material di Taman Nostalgia yang berada dalam kategori cukup baik $(60 \%$ - 79,99\%) berdasarkan skala likert adalah monumen gong perdamaian, monumen buku, bangku taman, jogging track, lampu taman, tempat sampah, dan toilet. Kondisi fisik elemen - elemen di ats memang terawat dan terpelihara dengan baik. Akan tetapi, elemen - elemen, seperti monumen buku, bangku taman, lampu taman sering menjadi sasaran perusakan dan coretan. Coretan - 
coretan sering berada di dinding bangunan. Beberapa fasilitas, seperti bangku taman sudah mendapat perawatan untuk menghilangkan coretan - coretan yang ada pada dinding bangunan. Tempat sampah yang berada di Taman Nostalgia terbuat dari drum bekas dan drum plastik. Tempat sampah di taman ini masih sangat dibutuhkan untuk mengatasi masalah sampah yang sering berserakan di taman. Kondisi toilet di Taman Nostalgia berada dalam kondisi yang cukup baik. Ketersediaan toilet ditaman ini belum memadai karena hanya 1 toilet yang berfungsi dan satunya masih dalam tahap penyelesaian pembangunan.

Tabel 1. Kondisi Fisik Hard Material berdsarkan Hasil Pengamatan

\begin{tabular}{|c|c|c|c|}
\hline No & Fasilitas & Kondisi & Keterangan \\
\hline 1 & $\begin{array}{l}\text { Monumen Gong } \\
\text { Perdamaian }\end{array}$ & Baik & Terawat secara baik \\
\hline 2 & Area Parkir & Baik & Belum ada penataan secara baik \\
\hline 3 & Area Kantin Makanan & Baik & Belum ada penataan secara baik \\
\hline 4 & Monumen Buku & Baik & Ada coretan - coretan \\
\hline 5 & Lapangan Basket & Baik & Ada bagian yang rusak \\
\hline 6 & Bangku Taman & Baik & Terawat secara baik \\
\hline 7 & Kolam & Baik & Tidak digunakan \\
\hline 8 & Jogging Track & Baik & Terawat secara baik \\
\hline 9 & Gazebo & Baik & Ada coretan - coretan \\
\hline 10 & Lampu Taman & Baik & Ada beberapa lampu hilang dan rusak \\
\hline 11 & Tempat Sampah & Baik & Terawat secara baik \\
\hline 12 & Toilet & Baik & $\begin{array}{c}1 \text { buah toilet sudah digunakan dan yang lainnya } \\
\text { masih dalam pembangunan }\end{array}$ \\
\hline
\end{tabular}

Sumber: Observasi

Kondisi fisik hard material yang berada dalam kategori baik (40\% - 59,99\%) berdasarkan skala Likert, antara lain area parkir, area kantin makanan, lapangan basket, kolam, dan gazebo. Elemen - elemen, seperti area parkir dan area kantin makanan telah dibentuk secara baik. Akan tetapi, penataan area parkir dan area kantin makanan secara optimal, akan meningkatkan estetika Taman Nostalgia. Area parkir bagian selatan sudah memiliki perkerasan, sedangkan area parkir bagian utara masih berupa tanah kosong. Penataan kedua sisi area parkir, akan bermanfaat bagi taman. Selain itu, area kantin makanan juga perlu ditata secara baik. Elemen yang lain, seperti gazebo dan lapangan basket masih penuh dengan coretan dan sasaran perusakan. Elemen - elemen ini perlu mendapatkan perbaikan dan perawatan secara baik agar dapat berfungsi secara optimal. Jogging track yang berada di Taman Nostalgia, memiliki kondisi yang baik dan sering dimanfaatkan sebagai sarana olahraga, terutama pagi dan sore hari. Kolam yang berada di Taman Nostalgia belum difungsikan secara baik. Kolam ini dapat ditata dan difungsikan sebagai kolam hias agar menghilangkan kesan kaku pada taman. 


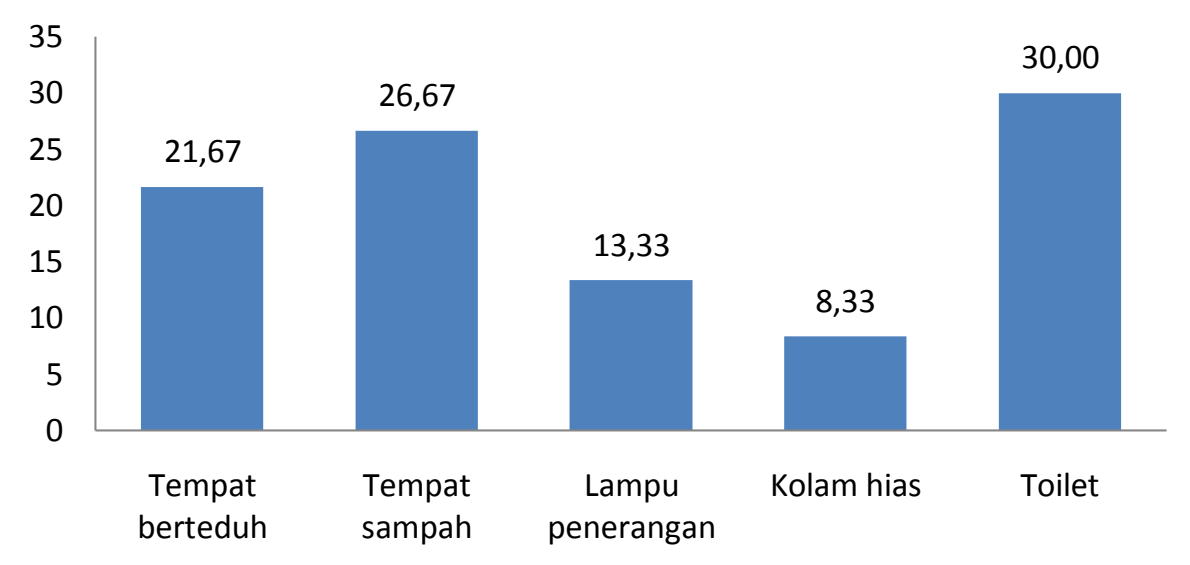

Gambar 5. Fasilitas yang Perlu ditambahkan di Taman Nostalgia

\subsubsection{Hasil Pengamatan Kondisi Fisik Soft Materials}

Tabel 2. Jenis Tanaman di Taman Nostalgia

\begin{tabular}{|c|c|c|c|c|c|}
\hline No & Nama Latin & Nama Lokal & Jenis & Kondisi & Fungsi \\
\hline 1 & Adenium coetaneum & Kamboja Jepang & Semak & Baik & Es \\
\hline 2 & Aglaonema & Aglonema & Semak & Baik & Es \\
\hline 3 & Alstonia scholaris & Pohon Pulai & Pohon & Baik & $\mathrm{Pt}$ \\
\hline 4 & Bougainvillea sp. & Bugenvil & Perdu & Baik & Es \\
\hline 5 & Canna hybrida & Bunga kana & Semak & Baik & Es \\
\hline 6 & Cassia siamea & Johar & Pohon & Baik & $\mathrm{Pt}$ \\
\hline 7 & Celosia cristata L. & Jengger ayam & Semak & Baik & Es \\
\hline 8 & Chlorophytum comosum & Lili paris & Semak & Baik & $\mathrm{Es}, \mathrm{Pb}$ \\
\hline 9 & Codiaeum variegatum & Puring & Semak & Baik & $\mathrm{Es}, \mathrm{Pa}$ \\
\hline 10 & Crinum asiaticum & Bakung & Perdu & Baik & Es \\
\hline 11 & Cuphea hyssopifolia & Kupea & Semak & Baik & Es \\
\hline 12 & Cycas revoluta & Sikas & Perdu & Baik & Es \\
\hline 13 & Delonix regia & Flamboyan & Pohon & Baik & Pt \\
\hline 14 & Gardenia augusta & Kaca piring & Perdu & Baik & Es \\
\hline 15 & Gliricidia sepium & Gamal & Pohon & Baik & $\mathrm{Pt}$ \\
\hline 16 & Hibiscus rosasinensis Linn. & Kembang sepatu & Perdu & Baik & Es \\
\hline 17 & Hyophorbe lagenicaulis & Palem botol & Pohon & Baik & Es \\
\hline 18 & Muntingia calabura & Kersen & Pohon & Baik & Pt \\
\hline 19 & Muscenda philipica & Nusa Indah & Perdu & Baik & Es \\
\hline 20 & Nerium Indicum & Kembang Mentega & Perdu & Baik & Es \\
\hline 21 & Plumeria rubra & Kembang jepun & Perdu & Baik & Es \\
\hline 22 & Polyalthia longifolia & Glodokan & Pohon & Baik & $\mathrm{Es}, \mathrm{Pa}$ \\
\hline 23 & Pterocarpus indicus & Angsana & Pohon & Baik & $\mathrm{Pt}$ \\
\hline 24 & Rhoeo discovio & Adam hawa & Semak & Baik & $\mathrm{Es}, \mathrm{Pb}$ \\
\hline 25 & Sansevieria trifasciata & Lidah mertua & Perdu & Baik & $\mathrm{Es}, \mathrm{Pb}$ \\
\hline 26 & Santalum Album Wild. & Cendana & Pohon & Baik & $\mathrm{Pt}$ \\
\hline 27 & Spathoglotis plicata & Anggrek tanah & Semak & Baik & Es, Gc \\
\hline 28 & Syzygium oleina & Pucuk merah & Perdu & Baik & Es, $\mathrm{Pa}$ \\
\hline
\end{tabular}

Keterangan : Es (Estetika), Pa(Pengarah), Pb(Pembatas),Pt(Peneduh),Gc(Penutup tanah) Sumber: Observasi 


\subsection{Permasalahan dan Penghambat Pemeliharaan Fisik di Taman Nostalgia}

\subsubsection{Faktor Fisik}

Faktor Fisik yang menjadi permasalahan dalam pemeliharaan fisik, meliputi sumber daya lahan - taman, bahan pemeliharaan, alat pemeliharaan, dan iklim. Karakteristik lanskap di wilayah Pulau Timor adalah sabana. Sabana merupakan hamparan lahan yang luas dan didominasi oleh semak dan rumput. Selain itu, tanah di Pulau Timor merupakan hasil pengangkatan, sehingga tanah di Kota Kupang banyak memiliki batuan berupa karang (Bappeda,2010). Dalam melakukan pemeliharaan fisik, sumber daya lahan taman juga menjadi penghambat. Hal ini juga berkaitan dengan ketersediaan air dan pertumbuhan tanaman di taman tersebut. Kelangkaan air di Kota Kupang pada musim kemarau yang berlangsung dalam waktu yang cukup lama, mengakibatkan pemeliharaan tanaman tidak dapat dilakukan secara optimal. Musim kemarau yang lebih lama mempengaruhi pertumbuhan dan perkembangan tanaman di Taman Nostalgia. Tanaman menjadi cepat meranggas, terutama tanaman berdaun lebar untuk mengurangi penguapan. Akan tetapi, hal ini berdampak pada penampilan tersebut dan pengaruhnya bagi estetika taman sendiri.

Tanaman yang berdaun lebar dan mudah meranggas pada musim kemarau, sebaiknya digantikan dengan tanaman yang lebih tahan terhadap sinar dan panas matahari pada musim kemarau. Pembudidayaan tanaman hias yang cocok dengan iklim Kota Kupang, dapat menjadi alternatif untuk mengatasi permasalahan tanaman berdaun lebar yang meranggas pada musim kemarau. Tanaman hias yang dibudidayakan dapat mengganti tanaman yang meranggas pada musim kemarau.

\subsubsection{Faktor Biologi}

Faktor biologi yang menjadi permasalahan dalam melakukan pemeliharaan fisik, meliputi jenis tanaman dan hewan atau satwa liar. Tanaman pohon lebih banyak ditanam karena keadaan iklim di Kota Kupang yang tergolong dalam Iklim tropis. Kota Kupang cenderung panas di waktu siang hari, sehingga membutuhkan lebih banyak tanaman berjenis pohon dengan fungsi sebagai peneduh. Tanaman berdaun lebar yang dipilih sebagai tanaman peneduh. Akan tetapi, pada musim kemarau, tanaman berdaun lebar akan lebih cepat meranggas. Penampilan tanaman yang kering akan mempengaruhi penampilan tanaman secara keseluruhan. Untuk mengatasi permasalahan ini, tanaman yang berdaun lebar dan cepat meranggas, dapat digantikan dengan tanaman - tanaman yang lebih tahan hidup pada musim - musim kemarau. Selain itu, pohon dengan daun yang selalu hijau sepanjang tahun (evergreen), tidak meranggas pada musim kemarau berguna sebagai penahan angin pada musim dingin. Sebaliknya pada musim panas tajuk pepohonan akan menahan sinar matahari dan memberikan kesejukan pada ruangan (Dahlan, 2011). Tanaman - tanaman yang dapat bertahan pada musim kemarau, antara lain bugenvil (bougenvil sp.) angsana (Pterocarpus indicus), ketapang (Terminalia cattapa), akasia (Acacia auriculformis) dan pinus (pinus merkusii). 


\subsubsection{Faktor Sosial Budaya}

Perilaku pengunjung merupakan permasalahan utama di Taman Nostalgia. Pengunjung Taman Nostalgia masih kurang memperhatikan aspek estetika taman. Perilaku vandalisme menjadi salah satu masalah yang terjadi di Taman Nostalgia. Vandalisme merupakan pengrusakan dengan sengaja terhadap benda - benda yang indah serta fasilitas umum atau pribadi,vandalisme yang umumnya terjadi dalam bentuk coret coret, bentuk lainnya, yaitu memotong pohon tanpa izin dan merusak tanaman (Utaminingtyas, 2012). Banyak fasilitas taman, seperti bangku taman, lampu taman, gazebo, dan lapangan basket yang dirusak dan dicoret secara sengaja. Selain itu, tanaman yang berada di Taman Nostalgia juga sering diambil dan dirusak secara sengaja oleh para pengunjung.Sampah juga menjadi permasalahan di Taman Nostalgia. Sampah sampah sisa - sisa makanan, bungkusan plastik dibuang sembarangan. Hal ini berdampak pada keindahan taman. Taman menjadi kotor dan tidak terawat. Tempat sampah yang telah disediakan oleh Dinas Kebersihan dan Pertamanan Kota Kupang, tidak digunakan secara optimal. Ketersediaan tempat sampah sudah mencukupi, tetapi penempatan tempat sampah sebaiknya diutamakan pada titik - titik orang beraktivitas, terutama di sekitar area kantin makanan.

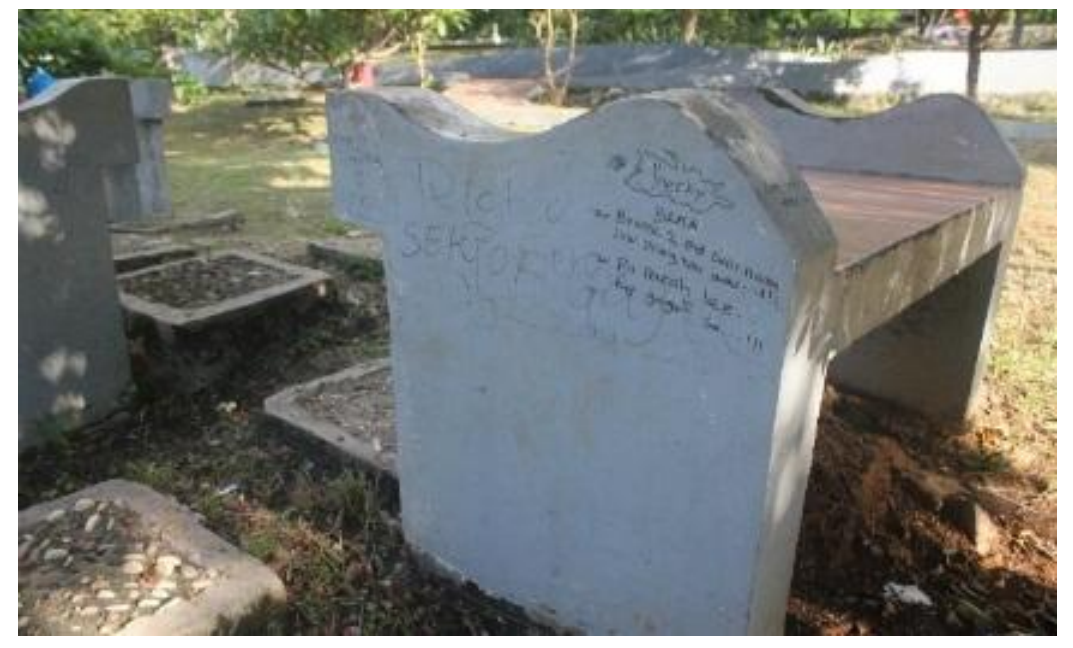

Gambar 6. Vandalisme di Taman Nostalgia

Perilaku pengunjung yang sering melakukan kegiatan vandalisme terhadap fasilitas dan elemen taman menjadi permasalahan penting di Taman Nostalgia. Permasalahan terhadap vandalisme dapat diatasi dengan beberapa cara, antara lain:

a. Menambah ketersediaan fasilitas tempat sampah dan melakukan penanganan cepat pada sampah yang telah ada sebelumnya serta pengangkutan sampah secara teratur, penempatan fasilitas pada titik-titik berkumpulnya pengunjung dan tersebar merata di setiap bagian setting, sehingga pengunjung tidak terlalu jauh untuk membuang sampah, selain itu desain tempat sampah yang menarik dan besarnya volume untuk kapasitas tempat sampah menjadi salah satu alternatif agar pengunjung membuang sampah pada tempatnya (Utamaningtyas, 2012). 
b. Pengelola taman sebaiknya melakukan pengawasan untuk mencegah aktivitas pengunjung yang tidak diinginkan. Pembagian shift untuk pengawas merupakan salah satu cara yang baik untuk melakukan pengawasan di taman ini. Penambahan lampu taman juga menjadi alternatif yang baik untuk memberikan penerangan di sekitar area taman. Hal ini akan memudahkan petugas lapangan melakukan pengawasan terhadap aktivitas yang tidak diinginkan, terutama di malam hari.

\subsubsection{Faktor Ekonomi}

Dalam melakukan pemeliharaan fisik terhadap elemen - elemen, faktor ketersediaan dana juga menjadi faktor penghambat. Dana yang dimanfaatkan untuk melakukan pengelolaan dan pemeliharaan fisik taman tidak mencukupi. Dana yang dimanfaatkan untuk melakukan pengelolaan dan pemeliharaan taman berasal dari anggaran yang diterima oleh Dinas Kebersihan dan Pertamanan. Akibatnya, aktivitas pemeliharaan tidak dapat dijalankan secara baik. Banyak fasilitas yang rusak, tidak dapat diperbaiki karena minimnya dana untuk pemeliharaan.

Para penjual makanan yang berdagang di Taman Nostalgia, tidak membayar sewa atau pungutan tempat, sehingga pemasukan untuk pengelola hanya berasal dari parkir. Para penjual makanan yang berada di Taman Nostalgia hanya membayar sewa penggunaan listrik di taman, sedangkan sewa pungutan tempat dibebaskan (Wawancara pribadi, 2015).

Perawatan ruang publik, seperti taman kota dapat dilakukan dengan kerja sama antara pihak pengelola dan para pedagang. Adanya kerja sama akan memperkecil biaya perawatan, serta mempermudah kinerja pengelola dalam pemeliharaan taman (Darmawan, 2009). Pengelola Taman Nostalgia sebaiknya melakukan pemungutan biaya bagi para penjual makanan untuk menambah pemasukan bagi pengelola dalam melakukan pemeliharaaan fasilitas - fasilitas taman maupun tanaman di taman tersebut. Sumber dana untuk melakukan pengelolaan dan pemeliharaan taman bisa juga berasal dari biaya parkir dan retribusi pedagang. Kerja sama antara pihak pengelola dan pedagang akan menambah biaya untuk pengelolaan dan pemeliharaan taman.

\section{Kesimpulan dan Saran}

\subsection{Kesimpulan}

1. Sistem pemeliharaan fisik di Taman Nostalgia, terdiri atas pemeliharaan fisik soft materials dan pemeliharaan fisik hard materials oleh Dinas Kebersihan dan Pertamanan Kota Kupang Provinsi Nusa Tenggara Timur. Pemeliharaan fisik soft materials, meliputi pembersihan area taman, penyiraman, pemupukan, pemangkasan, pemberantasan hama dan penyakit bagi tanaman. Pemeliharaan fisik hard materials, meliputi pemeliharaan bangunan taman dan fasilitas - fasilitas, serta perkerasan di taman.

2. Persepsi pengunjung terhadap pemeliharaan dan kondisi fisik hard materials dikategorikan baik sesuai dengan skala likert dan kondisi fisik tanaman (soft materials) tergolong baik sesuai hasil pengamatan di lapangan. 
3. Pemeliharaan fisik di Taman Nostalgia terhambat disebabkan oleh faktor fisik (kondisi tanah dan ketersediaan air di Kota Kupang), faktor biologi (penggunaan vegetasi, berupa tanaman yang cepat meranggas pada musim kemarau), faktor sosial budaya (aktivitas pengunjung,berupa pengrusakan fasilitas (vandalisme), serta faktor ekonomi (minimnya dana pemeliharaan yang digunakan oleh pengelola dalam melakukan pemeliharaan taman).

\subsection{Saran}

1. Jadwal pelaksanaan dan evaluasi pekerjaan perlu dilakukan secara teratur agar pemeliharaan lebih fokus dan intensif dalam pelaksanaannya.

2. Pihak pengelola sebaiknya menambah pekerja taman yang berkualitas dan memperhatikan keselamatan kerja dari pekerja taman.

3. Peraturan penggunaan taman perlu dibuat oleh Dinas Kebersihan dan Pertamanan Kota Kupang Provinsi Nusa Tenggara Timur dan pengadaan papan imbauan untuk mengurangi aktivitas vandalisme di taman.

4. Penambahan beberapa fasilitas di taman, seperti lampu taman dan tempat sampah, serta mengfungsikan kembali kolam hias dan toilet agar dapat digunakan secara optimal.

\section{Daftar Pustaka}

Bappeda. 2010. Profil Daerah Nusa Tenggara Timur Tahun 2010. https://pustakantt.googlecode.com/.../Profil\%20Daerah\%20NTT\%202010.pdf.Diakses tanggal 15 Mei 2015.

Dahlan, Endes. 2011. Bentuk dan Fungsi Hutan kota.

Darmawan, Edy. 2009. Ruang Publik dalam Arsitektur. Badan Penerbit Universitas Diponegoro, Jakarta: Kota..

Dinas Kebersihan dan Pertamanan Kota Kupang. 2015. Dokumen Pribadi.

Hakim, Rustam. 2011. Komponen Perancangan Arsitektur Lansekap Edisi Kedua. Bumi Aksara, Jakarta.

Hayon, Dewa. 2013. "Pemkot Didesak Perjelas Status Pengelolaan Tamnos". http://www.flobamora.net/berita/2834/2014-07-06/pemkot-didesak-perjelas-statuspengelolaan-tamnos.html. Diakses tanggal 23 Juni 2015

http://endesdahlan.staff.ipb.ac.id/files/2011/04/Bentuk-dan-Fungsi-HK.pdf. Diakses tanggal 20 Juli 2015

Silalahi, Ulber. 2012. Metode Penelitian Sosial. PT. Refika Aditama, Bandung.

Utamaningtyas, Annisa. 2012. Studi Hubungan Vandalisme dengan Setting Taman Lapangan Puputan Badung I Gusti Ngurah Made Agung Denpasar - Bali. E-Jurnal Agroekoteknologi Tropika, Vol.1, No.2, Oktober 2012.

UU No. 26 Tahun 2007. Tentang Penataan Ruang. Jurnal. URL: http://www.pu.go.id/satminkal/itjen/hukum/uu26-07.pdf. diakses tanggal 1 Maret 2015. 